\title{
35 Screening and assessment of learning policy
}

\author{
Kate Jacobs and Karen Starkiss
}

\section{How to use this policy}

Screening and assessment of student learning enables data-driven decisions regarding teaching and learning practices, allocation of resources, and referral of students for further assessment and intervention. This policy is intended to sit within a response to intervention (RTI) framework and should be created through consultation with general and specialist teaching staff, as well as relevant specialist support staff, such as speech-language pathologists and educational and developmental psychologists. Screening and assessment practices should be embedded school-wide and conducted multiple times throughout the school year. This policy is intentionally broad and school policy creators are encouraged to delete and build upon suggestions below to create a policy that best represents their school.

[To adapt and use this policy, delete or modify the text as indicated]

\section{[INSERT name of school] Screening and assessment of learning policy}

\section{Rationale}

All students are entitled to have access to a broad, balanced, and relevant curriculum that is differentiated to meet their individual needs and that affords them the opportunity to achieve their personal potential. Screening and assessment practices enable teachers and students to find out what the student knows and can do and how they can take their next steps in learning (Hattie, 2009). Assessment is inextricable from teaching; the quality of one is dependent on the quality of the other.

Systematic screening and assessment of learning aids teaching and learning practices, enables schools to evaluate the effectiveness of the curriculum, and acknowledges that individual students can have unique learning needs that, when met, enable them to reach their full potential and be included in the school community. This includes students with additional needs and disorders who require adjustments and additional support, as well as students who require extension and advancement. Further, systematic screening and assessment 


\section{Jacobs \& Starkiss}

allows for early identification of students at risk of below-expected achievement who require access to early intervention programs with strong evidence for producing reliable gains in academic attainment (e.g., Wanzek et al., 2018).

\section{Purpose}

The purpose of this policy is to outline the shared responsibility of the school community including school leadership, teaching staff, specialist support staff, and students in the systematic and regular process of screening and assessment of learning in order to drive teaching and learning practices, student progress, allocation of resources, and decisions regarding referrals for further assessment and intervention.

\section{Scope}

This policy applies to school leadership, teaching staff, and specialist staff at [INSERT name of school]. In addition, it encompasses students and parents in the process of assessment and outcomes.

[INSERT specific roles and responsibilities of individuals or teams]

\section{Policy statement}

Universal screening and assessment practices are a component of response to intervention (RTI), which involves a strategic approach to providing tiered evidence-based strategies for all students (Fletcher \& Vaughn, 2009; Fuchs \& Fuchs, 2006). Research supports the use of intensified academic interventions for students screened as at-risk for academic difficulties in reading (e.g., Gersten, et al., 2020; Wanzek et al., 2016), writing (e.g., Graham \& Perin, 2007), and maths (e.g., Fuchs et al., 2005).

The screening and assessment practices at [INSERT name of school] sit within an RTI framework and therefore are closely linked to whole-class interventions (Tier 1) and highlight students who require small group intervention (Tier 2) and those who need more specialist diagnostic assessments and intensive individualised educational support (Tier 3).

\section{School management}

Appropriate training and development of school staff provides the foundation for the implementation of systematic and effective screening and assessment practices that lead to improved student outcomes (Harlen, 2004). [INSERT name of school] provides school staff with appropriate professional development that assists staff to understand what they are screening or assessing; why they are screening or assessing; how to administer, score, and interpret the screening and/or assessment test; and how to make data-driven instructional 
decisions. [INSERT name of school] provides this professional development in the following ways: [adapt and adjust the following as needed]

- Identifies staff members to lead professional development activities and support individual staff

- Provides teachers and educational support staff with regular training and development in screening and assessment practices, new assessment tests, and interpretation and use of screening and assessment data

- Plans a yearly cycle of professional development to include training on assessment and interpretation of data

- Allocates additional staff members to support classrooms to carry out individual assessments as required

- Allocates time within the school timetable for staff to conduct moderations within year levels or subject areas

[INSERT name of school] employs a coaching approach to screening and assessment within an RTI framework (March et al., 2016; Glover, 2017) and identifies school staff who can act as coaches to support staff in a number of ways including: [adapt and adjust the following as needed]

- Interpreting screening and assessment data

- Using data to plan teaching and learning activities

- Understanding the triggers for additional intervention and/or assessment of individual students

[INSERT name of school] ensures space within the professional development program for teachers and leaders to develop and regularly revisit assessment policy and practice.

\section{Selection of screening and assessment tools}

[INSERT name of school] uses a range of assessment practices throughout the school year in order to support teaching and learning and to promote student achievement. These are highlighted on the Whole-School Screening and Assessment Schedule and include:

- Universal screening is introduced at the start of the school year to identify students who are at risk of learning difficulties despite having been provided with a scientific, evidence-based general education. Screening measures are easily implemented, scored, and interpreted by class teachers or subject/year leaders and are used on a wide scale (Boardman \& Vaughn, 2007; Jenkins et al., 2007). It establishes a baseline for student learning at both the group and individual level; however, it should be formative so as to inform teaching. 
- Assessment for learning (Formative) assesses knowledge, skills, and understanding and identifies gaps and misconceptions. It identifies if students are struggling, have consolidated learning, are ready to progress, or are working at greater depth. It is ongoing, allowing teachers to understand student performance on a continuing basis, and it actively informs pedagogy by directly impacting planning, strategies employed, teaching materials, feedback to students on progress towards targets, and the setting of class and individual student targets going forward (Clark, 2012; Lee et al., 2020).

- Assessment of learning (Summative) occurs at set times during the school year. It allows for evaluation of learning and the impact of teaching at the end of a period of time, as well as providing evidence of achievement against the objectives of the curriculum (Kennedy et al., 2008).

- Assessment as learning (Diagnostic) develops and supports students' metacognitive skills. It supports students becoming lifelong learners by enabling them to make sense of information, relate it to prior knowledge, and use it for new learning. Students develop a sense of ownership and efficacy when they use teacher, peer, and self-assessment feedback to make adjustments, improvements, and changes to what they understand (Schunk, 1996).

- Teacher diagnostic assessment is carried out by appropriately qualified professionals when screening and assessment practices identify a student with additional needs that requires an in-depth diagnostic assessment to inform intervention (generally occurs at Tier 2).

- Specialist diagnostic assessment is carried out by appropriately qualified professionals (such as speech-language pathologists and/or educational and developmental psychologists) when screening and assessment practices identify a student with additional needs that requires an in-depth diagnostic assessment to determine appropriate intervention and diagnostic categories if applicable (generally occurs at Tier 3).

[INSERT name of school] selects screening and assessment tools on the basis of research evidence regarding the predictive ability of future academic outcomes (e.g., Gersten et al., 2012; National Reading Panel et al., 2000; Rose, 2006; Rowe, 2005).

[INSERT name of school] uses selected screening measures consistently for at least a full school year so that school staff can act on the data collected and avoid the consequences associated with changing screening measures during the school year, such as loss of baseline data, the need to retrain school staff, and confusion for staff and students (Hall, 2008).

\section{Recording and reporting of screening and assessment data}

[INSERT name of school] has a process for formally recording screening and assessment data so that it can be quickly and easily accessed by relevant staff. 
[INSERT name of school] encourages the use of both formal and informal screening and assessment data in teacher plans, feedback, and target setting in students' workbooks, reports to parents, and in individual learning plans.

[INSERT name of school] provides staff with set times within the school calendar to administer, score, and record screening and assessment data.

[INSERT name of school] uses reporting to communicate comprehensive information about student learning and achievement in different forms to a range of audiences for a variety of purposes. Accurate reporting of formative and summative assessment information provides feedback to students, parents, and teachers about what students know and can do, together with recommendations for their future learning. The information is also valuable for school and system-wide decision making and planning. [INSERT name of school] reports information in the following ways: [adapt and adjust the following as needed]

- Twice-yearly reports to parents regarding student progress

- Parent-teacher interviews

- Student-teacher interviews

- Student support group meetings for students identified with additional needs

- Reports to educational authorities, school governance, or councils

\section{Equal opportunities}

[INSERT name of school] uses screening and assessment to effectively and systematically identify the individual needs of all students. It supports equal opportunity for all students by enabling students with additional needs and disabilities, students who excel, and students for whom English is an additional language to be provided with a curriculum which meets their needs.

\section{Students with additional needs}

When there is an indication that a student's difficulties are impacting on their learning and demonstration of achievement, [INSERT name of school] employs adjusted assessment procedures. We consult with parents and students, as well as internal and external specialists as necessary, to determine the appropriate forms that assessment may take, such as: [adapt and adjust the following as needed]

- Verbal as opposed to written tests

- Provision of a reader or scribe

- Provision of assistive technology

- Additional time

- Reduced output 


\section{Assessment moderation}

Moderation involves teachers sharing and developing their understanding of what learning looks like by examining examples of different types and quality of students' work and comparing these with formal standards and success criteria. [INSERT name of school] recognises that for moderation to be effective in positively impacting teaching, learning, and student progress, it requires collaborative discussion of student work based on predetermined assessment criteria (Maxwell, 2010). Moderation strengthens other assessment practices by providing a structure and process for teaching teams, teachers, classes, and individual students to develop a shared and deep understanding of learning intentions, success criteria, and the curriculum standards on which assessment is based (Meiers et al., 2007).

[INSERT name of school] allocates time within the school timetable for staff and students to conduct moderations that can occur within the class, within year levels, or within subject areas.

\section{Monitoring and evaluation}

[INSERT name of school] will monitor and evaluate the effectiveness of the screening and assessment policy annually and make changes as necessary from evidence of student progress, discussions within the school community, and new research evidence.

\section{Authorship}

Dr Kate Jacobs, Monash University

Karen Starkiss, Dyslexia Assessment and Support Services

[INSERT RELEVANT STAFF MEMBERS]

\section{Related policy and documents}

[INSERT RELEVANT POLICY AND DOCUMENTS]

\section{Date of ratification}

This policy was ratified on the [INSERT DATE].

\section{Date of review}

This policy will be reviewed by [INSERT DATE]. 


\section{Rating of evidence base}

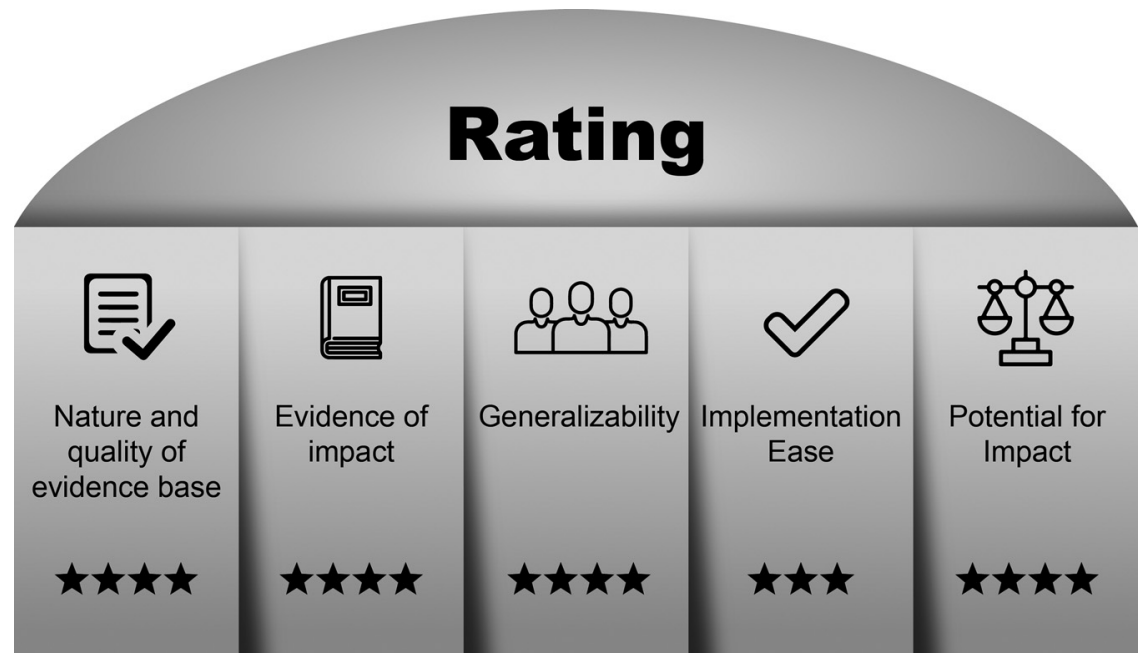

Figure 35.1. Screening and Assessment of Learning Rating of Evidence.

Author Note. The policy is built from a large and established body of work that spans many countries. When the policy is applied as part of a whole-school adoption of RTI, then the impact is strong as students requiring additional intervention, as well as those requiring advancement, are identified early and their needs met. Screening and assessment practices are used with all students, in all types of schools regardless of individual differences such as language, culture, and socioeconomic status. In a whole-school approach to screening and assessment, time and funds are required for training and resourcing. Strong leadership and consistency are also integral to the success of this policy. This policy can promote significant gains in student achievement, behaviour, and wellbeing as it enables the individual learning needs of all students to be identified and met.

\section{Further reading}

Dexter, D. D., \& Hughes, C. (n.d.). Progress monitoring within a response-tointervention model. RIT Action Network. http://www.rtinetwork.org/learn/ research/progress-monitoring-within-a-rti-model

Hughes, C., \& Dexter, D. D. (n.d.). Universal screening within a response-tointervention model. RIT Action Network. http://www.rtinetwork.org/learn/ research/universal-screening-within-a-rti-model

Salinger, R. L. (2016). Selecting universal screening measures to identify students at risk academically. Intervention in School and Clinic, 52(2), 1-8.

\section{References}

Boardman, A. G., \& Vaughn, S. (2007). Response to intervention as a framework for the prevention and identification of learning disabilities: Which comes first, 
identification or intervention? In J. B. Crockett, M. M. Gerber, \& T. J. Landrum (Eds.), Achieving the radical reform of special education: Essays in honor of James M. Kauffman (pp. 15-35). Erlbaum.

Clark, I. (2012). Formative assessment: Assessment is for self-regulated learning. Educational Psychology Review, 24(2), 205-249.

Fletcher, J. M., \& Vaughn, S. (2009). Response to intervention: Preventing and remediating academic difficulties. Child Development Perspectives, 3(1), 30-37.

Fuchs, L. S., Compton, D. L., Fuchs, D., Paulsen, K., Bryant, J. D., \& Hamlett, C. L. (2005). The prevention, identification, and cognitive determinants of math difficulty. Journal of Educational Psychology, 97(3), 493-513.

Fuchs, D., \& Fuchs, L. S. (2006). Introduction to response to intervention: What, why, and how valid is it? Reading Research Quarterly, 41(1), 93-99.

Gersten, R. M., Clarke, B., Jordan, N., Newman-Gonchar, R., Haymond, K., \& Wilkins, C. (2012). Universal screening in mathematics for the primary grades: Beginnings of a research base. Exceptional Children, 78(4), 423-445.

Gersten, R., Haymond, K., Newman-Gonchar, R., Dimino, J., \& Jayanthi, M. (2020). Meta-analysis of the impact of reading interventions for students in the primary grades. Journal of Research on Educational Effectiveness, 13(2), 401-427.

Glover, T. A. (2017). A data-driven coaching model used to promote students' response to early reading intervention. Theory Into Practice, 56(1), 13-20.

Graham, S., \& Perin, D. (2007). A meta-analysis of writing instruction for adolescent students. Journal of Educational Psychology, 99(3), 445-476.

Hall, S. L. (2008). Implementing response to intervention: A principal's guide. Corwin Press.

Harlen, W. (2004). A systematic review of the evidence of reliability and validity of assessment by teachers used for summative purposes. EPPI-Centre, University of London. https://eppi.ioe.ac.uk/cms/Portals/0/PDF\%20reviews\%20and\%20summaries/ass_rv3. pdf?ver=2006-03-02-124720-170

Hattie, J. (2009). Visible learning: A synthesis of over 800 meta-analyses relating to achievement. Routledge.

Jenkins, J. R., Hudson, R. F., \& Johnson, E. S. (2007). Screening for at-risk readers in a response to intervention framework. School Psychology Review, 36(4), 582-600.

Kennedy, K. J., Chan, J. K. S., Fok, P. K., \& Yu, W. M. (2008). Forms of assessment and their potential for enhancing learning: conceptual and cultural issues. Educational Research for Policy Practice, 7, 197-207.

Lee, H., Chung, H. Q., Zhang, Y., Abedi, J., \& Warschauer, M. (2020). The effectiveness and features of formative assessment in US K-12 education: A systematic review. Applied Measurement in Education, 33(2), 124-140.

March, A. L., Castillo, J. M., Batsche, G. M., \& Kincaid, D. (2016). Relationship between systems coaching and problem-solving implementation fidelity in a responseto-intervention model. Journal of Applied School Psychology, 32(2), 147-177.

Maxwell, G. S. (2010). Moderation of student work by teachers. In E. Baker, P. Peterson \& B. McGaw (Eds.), International encyclopedia of education (3rd ed., pp. 457-463). Elsevier.

Meiers, M., Ozolins, C., \& McKenize, P. (2007). Improving consistency in teacher judgements: An investigation for the department of education, Victoria. Australian Council for Educational Research.

National Reading Panel (US), National Institute of Child Health, Human Development (US), National Reading Excellence Initiative, National Institute for Literacy 
(US), United States Public Health Service, \& United States Department of Health. (2000). Report of the National Reading Panel: Teaching children to read: An evidence-based assessment of the scientific research literature on reading and its implications for reading instruction: Reports of the subgroups. National Institute of Child Health and Human Development, National Institutes of Health. https://www.nichd. nih.gov/sites/default/files/publications/pubs/nrp/Documents/report.pdf

Rose, J. (2006) Independent review of the teaching of early reading. https://dera.ioe.ac. uk/5551/2/report.pdf

Rowe, K. (2005). National inquiry into the teaching of literacy. ACER. https://research. acer.edu.au/tll_misc/5/

Schunk, D. H. (1996). Learning theories: An educational perspective (2nd ed.). Merrill.

Wanzek, J., Stevens, E. A., Williams, K. J., Scammacca, N., Vaughn, S., \& Sargent, K. (2018). Current evidence on the effects of intensive early reading interventions. Journal of Learning Disabilities, 51(6), 612-624.

Wanzek, J., Vaughn, S., Scammacca, N., Gatlin, B., Walker, M. A., \& Capin, P. (2016). Meta-analyses of the effects of tier 2 type reading interventions in Grades K-3. Educational Psychology Review, 28, 551-576. 